\title{
Determination of bisphenol $A$ in beer by immunoaffinity column tandem high-performance liquid chromatography
}

\author{
K.H. LI, L.X. ZHU, R.R. LIU \& W. Meng. \\ School of Life Science, Jiangxi Science \&Technology Normal University, Jiangxi, Nanchang, \\ China
}

KEYWORD: bisphenol A; immune-affinity column; high-performance liquid chromatography ABSTRACT: A rapid and sensitive method using immuno-affinity columns (IACs) as sample purification procedure and high-performance liquid chromatography (HPLC) tandem fluorescence detector (FLD) for detection has been developed for the determination of bisphenol A (BPA) in beer. The limit of detection (LOD) is $0.28 \mathrm{ng} / \mathrm{ml}(\mathrm{S} / \mathrm{N}=3)$ and the limit of quantity (LOQ) is $0.95 \mathrm{ng} / \mathrm{ml}$ $(\mathrm{S} / \mathrm{N}=10)$. For standard adding and recovery experiments toward beer sample with addition of fourlevel bisphenol A, the average recovery ratio range from $74.56 \%$ to $97.60 \%$, and the relative standard deviations (RSD) range $1.04 \%$ to $9.77 \%$. In conclusion, this method is an appropriate way for detection of BPA. For the detection of canned beer samples of various brands, the detection rate is as high as $100 \%$.

\section{Introduction}

Bisphenol A (BPA) is a compound what has a simple and symmetrical structure. Figure. 1 shows the chemical structural formula of BPA (Inoue, $\mathrm{K}$ et al 2000). Pure BPA is white crystal. BPA dissolves easily in alkaline solvent and polar solvent such as sterols, ether, and acetone. BPA has various toxicities, such as immunotoxicity, neurotoxicity, and genotoxicity. And for mostly reported is its effect on inducing female precocity and male infertility (Watanabe, T, 2001).

BPA is mainly used for the synthesis of various polymeric materials. And about ninety percent, BPA is used as a raw material for polycarbonate (PC) and epoxy resin to produce various products. PC is usually used as containers such as baby bottles and later PC is forbidden to be used as baby bottles because of its various toxicity (Maiolini, E et al. 2014). Epoxy resin is mainly used as paint coat for pop can. Beer is an alcoholic beverage what is popular among humans. Canned beer is hot sellers in supermarket all over the world. BPA dissolves easily in alcohol, so BPA is prone to migrate from tank coating to beer where a potential harm is exist.

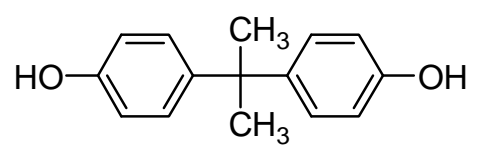

Figure 1. The chemical structure of BPA

The methods for detection of BPA are various, such as GC-MC (Becerra, V \& Odermatt, J, 2012); HPLC (Hadjmohammadi, M.R, 2010); Enzyme-linked immunosorbent assay (ELISA) (Zheng, J et al). What's more, immunochromatographic (Mei, Z.L et al, 2013) was also reported for detection of BPA.

Immunoaffinity columns were used in sample pretreatment to purify samples. It based on the specific binding of antigen and antibody. When the antigen flows through the column, the corresponding antibody would recognize and combine with them. During the past few years, the use of antibodybased immunoaffinity columns in the clean-up has given a strong impulse to the improvement of mycotoxin analysis (Visconti, A et al.1999). Immunoaffinity columns have already been successfully applied to purification of extracts for the analysis of several mycotoxins in various food matrices (Pascale, $M$ et al. 2003). For example, Visconti, A et al use IACs for sample clean-up and LC to detection the ochratoxin A (OA) in domestic and beers (Visconti, A et al, 2000). It is reported that IACs-LC are also used for detection of aflatoxins, ochratoxin A, and zearalenone in grains (Göbel, $\mathrm{R}$ and LUSKY, K, 2004). 
In this study, through extraction and purification by a BPA immuno-affinity column, the interference caused by matrix was reduced, and the ratio of the recovery was improved, the reported method implied a sensitive and efficient detection approach for BPA in canned beer.

\section{Materials and methods}

\section{Reagents and instrument}

Methanol (HPLC grade) was purchased from Sigma. Immune-affinity columns of BPA were made by ourselves. BPA standard of CP grade was purchased from CHENGDU BOON STREAM CHEMICAL INDUSTRY. Water was purified with Milli-Q water purification system (Millipore, USA). Agilent 1100 system was purchased from Agilent technology (Agilent, USA).

\section{Sample treatment}

The canned beers were obtained from a supermarket. The proteins contented in beer were the main interference for detection of BPA, so we took action of heating to eliminate the obstruction. Beer was heated at $80^{\circ} \mathrm{C}$ first to denature proteins, and then filtrated and diluted by ultrapure water to make the concentration of BPA range from $2 \mathrm{ng} / \mathrm{ml}$ to $5 \mathrm{ng} / \mathrm{ml}$. Then the dilution liquid was dropped through the immune-affinity column at the speed of $1 \mathrm{~d} / \mathrm{s}$ (a drop of one minute). Immuno-affinity column was washed by $15 \mathrm{ml}$ ultrapure water when the dilution liquid dropped through the immunoaffinity column completely. Finally, BPA was eluted by $4 \mathrm{ml}$ methanol from immune-affinity column. Nitrogen was used to blow-dry the methanol. The leavings was solved by $1 \mathrm{ml}$ methanol-water $(55: 45)$ and prepared for HPLC. The content of BPA in canned beer was calculated according to Equation.1:

$$
C_{X}=\frac{C V-C_{0} V}{V_{X}}
$$

where $\mathrm{C}_{\mathrm{X}}$ is the concentration of BPA in canned beer; $\mathrm{C}$ and $\mathrm{C}_{0}$ are the concentration of BPA for standard adding sample and standard free sample respectively; $\mathrm{V}$ and $\mathrm{V}_{\mathrm{X}}$ are the volume of the final treated sample prepared for HPLC and the volume of canned beer before treatment, respectively.

The standard adding and recovery experiments were adding BPA standard of known quantity and the later treatment was same as the mentioned above. The recovery ratios were acceptable between $80 \% \sim 120 \%$ according to the expression (Eq. 2):

$$
R \%=\frac{C V-C_{0} V}{X} \times 100 \%
$$

where $\mathrm{R} \%$ is recovery ratio; $\mathrm{C}$ and $\mathrm{C}_{0}$ are the concentration of $\mathrm{BPA}$ for standard adding sample and standard free sample respectively; $\mathrm{X}$ is the mass of adding standards.

\section{Chromatographic condition of HPLC}

The method used an Agilent LC column whose type is ZORBAX Eclipse Plus C18 4.6*150 mm, 3.5 $\mu \mathrm{m}$. The BPA was separated with methanol-water $(55: 45, \mathrm{v} / \mathrm{v})$ as a mobile phase at a flow-rate of 0.8 $\mathrm{ml} / \mathrm{min}$. The injection volume was $100 \mu \mathrm{l}$. The excitation and emission wavelengths were $227 \mathrm{~nm}$ and $313 \mathrm{~nm}$, respectively, for FLD. The temperature of column heaters was $30{ }^{\circ} \mathrm{C}$.

\section{The calibration curve}

The standard solutions of BPA were prepared by dilution of a stock standard solution and the concentrations ranged $1 \mathrm{ng} / \mathrm{ml}$ to $200 \mathrm{ng} / \mathrm{ml}$.

\section{Results and discussion}

\section{The calibration curve}

Ten BPA working standard solutions were diluted to $0.5 \mathrm{ng} / \mathrm{ml}, 1 \mathrm{ng} / \mathrm{ml}, 2.5 \mathrm{ng} / \mathrm{ml}, 5 \mathrm{ng} / \mathrm{ml}, 10$ $\mathrm{ng} / \mathrm{ml}, 25 \mathrm{ng} / \mathrm{ml}, 50 \mathrm{ng} / \mathrm{ml}, 100 \mathrm{ng} / \mathrm{ml}$, and $200 \mathrm{ng} / \mathrm{ml}$. The abscissa of the curve was the concentration of BPA standard solutions and the ordinates of the curve was peak area. The chromatograms of BPA standard and the calibration curve were showed in Figure. 2 and Figure. 3 respectively.

From Figure. 2 we can find that the elution time of BPA was $10.471 \mathrm{~min}$ and peak shape of BPA is well. 
From Figure. 3 we can find that the workings curve with a concentration ranging in $1 \sim 200 \mathrm{ng} / \mathrm{ml}$ showed a good linearity correlation $(\mathrm{R}=1)$ and was represented by the Equation 3:

$y=44.097 x+7.2839$

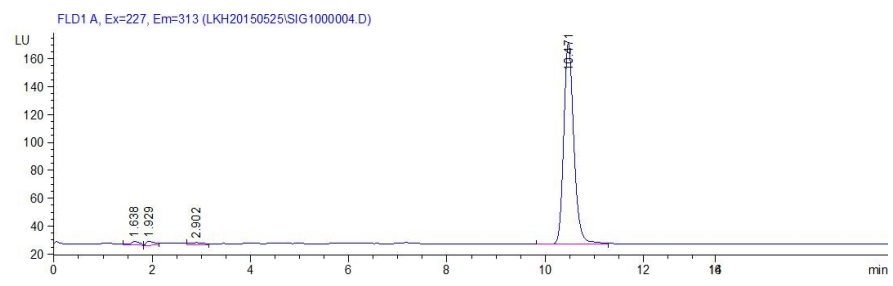

Figure. 2 The chromatograms of BPA standard

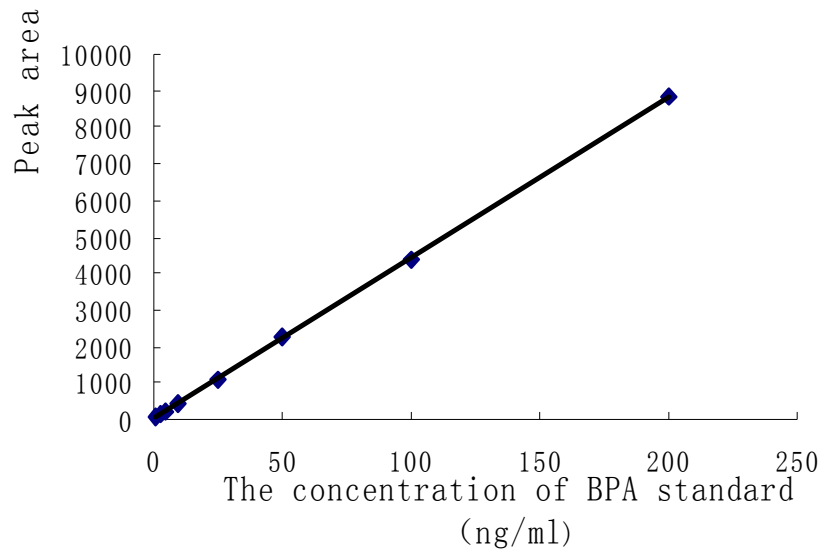

Figure. 3 The calibration curve

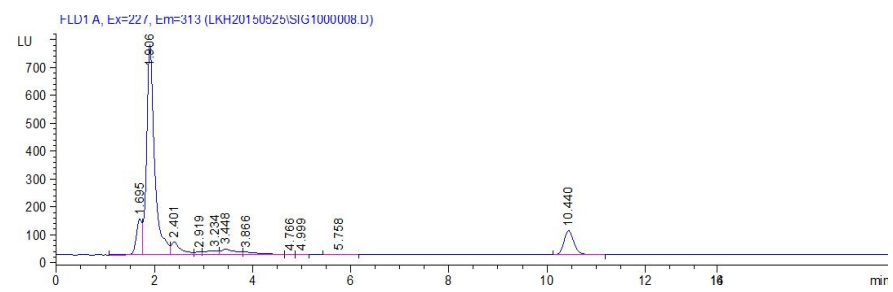

Figure. 4 The chromatograms of extracted beer sample.

\section{The result of sample extracted}

Figure. 4 shows the chromatograms of extracted beer sample.

From Figure. 4 we can see that there is a peak at 10.440 min. Compared with the peak of BPA standard, the peak can regard as the peak of BPA. And there are little impure peaks what prove that the method we used to extract is feasible.

The result of standard adding and recovery experiment

For standard adding and recovery experiments toward beer sample with addition of four-level BPA all shows good recovery ratios (Tab. 1).

Table. 1 Recovery ratios of standard adding and recovery experiments

\begin{tabular}{lcccc}
\hline $\begin{array}{l}\text { Adding standard } \\
\text { (ng) }\end{array}$ & 100 & 300 & 500 & 1000 \\
& & & & \\
\hline $\begin{array}{c}\text { Average recovery ratio } \\
(\%)\end{array}$ & 74.56 & 97.60 & 82.78 & 91.49 \\
RSD value(\%) & 6.54 & 8.19 & 9.77 & 1.04
\end{tabular}


From Table. 1 we can see that the average recovery ratios range from $74.56 \%$ to $97.60 \%$ and the RSD value range from $1.04 \%$ to $9.77 \%$. It shows the good accuracy of that method for BPA.

\section{The result of real sample detection}

The analysis of six brands canned beer obtained from a supermarket carried under the condition related above. The analyzed samples were representative of various brands of caned beer in China market. The result of the analysis present in Table. 2 .

Table. 2 The concentration of BPA in real sample

\begin{tabular}{llc}
\hline Brands & $\begin{array}{l}\text { the concentration } \\
\text { concentration of BPA }(\mathrm{ng} / \mathrm{ml}) \\
\text { of BPA }(\mathrm{ng} / \mathrm{ml})\end{array}$ & $\begin{array}{c}\text { Brands } \\
\text { the }\end{array}$ \\
\hline 1.27 & 3.05 & 4 \\
2 & 4.12 & 5 \\
1.57 & 1.73 & 6 \\
3 & & \\
1.45 & & \\
\hline
\end{tabular}

\section{Conclusions}

BPA used as additive for food packaging material has an intimate relation to human's health. The method established for detection of BPA is simple and dependable. It has good recovery ratio and RSD value, so it shows a good accuracy. The LOD and LOQ were $0.28 \mathrm{ng} / \mathrm{ml}(\mathrm{S} / \mathrm{N}=3)$ and $0.95 \mathrm{ng} / \mathrm{ml}$ $(\mathrm{S} / \mathrm{N}=10)$ respectively, so it also shows a good sensitivity. The method for sample extracted is easy. And the application of immune-affinity column shows an advantage to obtain a clean sample. On the other hand, the use of immune-affinity column also increases the reliability for detection.

\section{Acknowledgement}

This work was financially supported by grants from Natural Science Foundation of Jiangxi Province (No. 20122BAB214006, 20132BAB214004) and Science Foundation of Jiangxi Educational Bureau (No.GJJ13573).

\section{REFERENCES}

[1] Becerra, V \& Odermatt, J. 2012. Detection and quantification of traces of bisphenol A and bisphenol S in paper samples using analytical pyrolysis-GC/MS. Analyst, 137: 2250-2259.

[2] Göbel R \& Lusky K. 2004. Simultaneous determination of aflatoxins, ochratoxin A, and zearalenone in grains by new immunoaffinity column/liquid chromatography. Journal of AOAC International, 87(2): 411-416.

[3] Hadjmohammadi, M.R. 2010. Determination of bisphenol A in Iranian packaged milk by solidphase extraction and HPLC. Monatsh Chem, 141: 501-506.

[4] Inoue, $\mathrm{K}$ et al. 2000. Determination of bisphenol $\mathrm{A}$ in human serum by high-performance liquid chromatography with multi-electrode electrochemical. J. Chromatogr, 749: 17-23.

[5] Mei, Z.L. 2013. Immunochromatographic lateral flow strip for on-site detection of bisphenol A. Microchim Acta, 180:279-285.

[6] Maiolini, E et al. 2014. Bisphenol A determination in baby bottles by chemilumines-cence enzyme-linked immunosorbent assay, lateral flow immunoassay and liquid chromatography tandem mass spectrometry. Analyst. 139(1): 318-324.

[7] Pascale, $M$ et al. 2003. Determination of T-2 toxin in cereal grains by liquid chromatography with fluorescence detection after immunoaffinity column clean-up and derivatization with 1anthroylnitrile. Journal of Chromatography A, 989(2): 257-264.

[8] Visconti, A et al. 1999. Determination of ochratoxin A in wine by means of immunoaffinity column clean-up and high-performance liquid chromatography. Journal of Chromatography A, 864(1): 89-101.

[9] Visconti, A et al. 2000. Determination of ochratoxin A in domestic and imported beers in Italy by immunoaffinity clean-up and liquid chromatography. Journal of Chromatography A. 888(1): 321-326. 
[10] Watanabe, T. 2001. Development of sensitive high-performance liquid chromatography with fluorescence detection using 4-(4,5-diphenyl-1H-imidazol-2-yl)-benzoyl chloride as a labeling reagent for determination of bisphenol A in plasma samples. Journal of Chromatography B, 762: 17.

[11]Zheng, J et al. 2011. Detection of bisphenol A in water samples using ELISA determination method. Water Science \& Technology: Water Supply. 11: 57-60. 